\title{
Lively Children Trapped in an Island of Disadvantage: Verbal Play of Cantonese Working Class Schoolboys in Hong Kong
}

\author{
Angel Mei Yi Lin, Ph.D., Assistant Professor \\ Department of English, City University of Hong Kong \\ Tat Chee Ave, Kln., Hong Kong \\ E-mail: enangel@cityu.edu.hk
}

Phone: (852) 2788-8122

Fax: (852) 2788-8894

(In: International Journal of the Sociology of Language, 143 (2000), pp. 63-83)

\begin{abstract}
In this paper I describe the mocking and playful verbal practices of some Cantonese working class secondary schoolboys in an English language lesson in Hong Kong. I show how these Cantonese-speaking adolescents seek to assert their indigenous identity and their ingenious Cantonese competence in an educational system that places Cantonese at the bottom of the hierarchy of languages. These self-asserting verbal practices of working class schoolboys, while in themselves artful and playful, do not contribute to the breaking through of the reproduction and perpetuation of these schoolboys' subordinated and insulated Cantonese sociocultural world, where there is little access to the socioeconomically dominant symbolic resource of English. Without access to English, they can hardly access the middle class bilingual identity and the socioeconomic success and social status that come with it. Paradoxically, by doing resistance to an alienating English curriculum, they contribute to the perpetuation of their own insularity and subordination and are trapped in a cycle of disadvantage. The paper concludes with a discussion of the possible impact of the transition of Hong Kong from a British colony to a Special Administrative Region (SAR) of China on language, identity, and social class in post-1997 Hong Kong.
\end{abstract}

\section{General Background: The Symbolic Domination of English in Hong Kong}

Before July 1, 1997, Hong Kong was a British colony situated on the southern coast of China. Since its cession from China to Britain in 1842 as a result of China's defeat in the Opium War, it has changed from an agrarian fishing port to a labour-intensive industrial city in the 1960s and 70s. In the 1980s and 90s, with the boom of China trade following "the open door" policy of China, Hong Kong has gradually changed from a light-industry 
based, manufacturing economy to an economy primarily based on the re-export of products processed in China, and business and financial servicing for China (Ho 1994). Today, it is also one of the largest and busiest international financial centres in the world, attracting a large number of Chinese, Asian and Western speculators and investors.

Despite its international cosmopolitan appearance Hong Kong is ethnically rather homogeneous. About $97 \%$ of its population is ethnic Chinese, and Cantonese is the mother tongue of the majority. English native speakers account for not more than 3\% of the entire population. They constituted the dominant class, at least until July 1st, 1997 when the sovereignty of the colony was returned to China and Hong Kong became a Special Administrative Region of that country.

Notwithstanding its being the mother tongue of only a minority, English is both the language of power and the language of educational and socioeconomic advancement, i.e., the dominant symbolic resource in the symbolic market (Bourdieu 1982/1991) in Hong Kong.

The symbolic market is embodied and enacted in the many key situations (e.g., educational settings, job settings) in which symbolic resources (e.g., certain types of linguistic skills, cultural knowledge, specialized knowledge and skills) are demanded of social actors if they want to gain access to valuable social, educational and eventually material resources (ibid.). For instance, Hong Kong students must have adequate English resources, in addition to subject matter knowledge and skills, to enter and succeed in English-medium professional training programmes that earn for them English-accredited credentials necessary for high-income professions such as medicine, dentistry, architecture, accountancy, and legal studies. The symbolic market is therefore not a metaphor, but one with transactions that have material, socioeconomic consequences for people (for a detailed account of the symbolic domination of English in Hong Kong, see Lin, 1996a). Even after July 1, 1997, there has been no sign of a decrease in the socioeconomic importance of English. 


\section{Reproducing Their Insulated Cantonese Sociocultural World: Doing English lessons in low socioeconomic background schools in Hong Kong}

The reading lesson data and analysis reported in this paper were taken from a larger study (Lin 1996b) which examined how English language lessons were organized in junior forms (Form 1-3; comparable to Grade 7-9 in North America) in secondary schools in Hong Kong to find out whether schools situated in different socioeconomic contexts afford differential degrees of access to English. In the study, I visited and videotaped the English lessons on five or more consecutive school days in each of the eight English classes of the eight teachers who participated in the study. The eight teachers were drawn from seven schools from a range of socioeconomic and academic backgrounds. I informally interviewed small groups of students, and collected other curricular, assessment, and background information on the classes and the schools.

The results of a fine-grained discourse analysis of the classroom data in the larger study show that with one exception the English lessons in schools situated in disadvantaged socioeconomic contexts, where there is little access to English outside the classroom, are characterized by meaning-reduced, linguistic-operations-oriented activities (for details, see Lin, 1996b). Doing English lessons in these classrooms seems to have the effect of reproducing the students' insulated Cantonese sociocultural world and their lack of interest in and access to English linguistic and sociocultural resources. These students and their families typically live in a lifeworld which is insulated from any extended, authentic English communicative, literacy, or sociocultural activities. Their school worlds are also isolated from any English speech communities. Typically, they are located in low SES (socioeconomic status) public housing estates (government-subsidized housing), which are both physically and socially distanced from any clusters of native English or Englishconversant speakers, who seldom live in low SES areas in Hong Kong.

\section{The General Context of the English Reading Lesson}

The reading lesson segments to be examined in this paper were taken from a larger corpus of English lesson data videotaped in the class of one teacher (Mr. Chan) ${ }^{1}$ over three consecutive weeks. The examples found in the lesson segment were not ideographic examples: similar examples could be found in the larger corpus of the data. 
English reading lessons are an integral part of the English language curriculum in Hong Kong schools. Although all schools follow the "same" curriculum (i.e., suggested syllabus, teaching targets, sequence, and methodology) prescribed by the Hong Kong Education Department, schools of different banding ${ }^{2}$ use different textbooks which are widely understood among school principals, teachers and textbook publishers to cater to students of different English proficiency levels even though they are at the same grade level. The reading textbook (the storybook, "Chinese Myths") used in Mr. Chan's class is an example of those English textbooks that aim at catering for lower banding students with low English proficiency. They are typically written in an uninteresting way and are usually about cultural topics that are supposed to be familiar to the local Cantonese students (e.g., Chinese myths).

Different kinds of teachers are typically employed in different bands of schools. For instance, Band 1 schools are more prestigious and their students have the reputation of having good academic performance and learning attitudes. These schools tend to attract the most qualified teachers, for example, teachers who have specialized in English language or English literature in higher education. On the other hand, lower banding schools usually have the reputation of having students who are poorer in both academic and behavioural terms and these schools usually have to employ teachers who have not majored in English language or English literature in their higher education to teach English. This is the consequence of a constant shortage of English graduates for school teaching positions. English-conversant graduates usually find higher-social-status jobs in the fields of business or government administration in Hong Kong. The Education Department does not require a secondary school English teacher to have a qualification in English language/literature, but accept qualifications in any subject, e.g., History, Geography, Sociology, Psychology. The lesson segment to be examined in this paper was taken from an average class in a Band 2 school and the English teacher (Mr. Chan) for the class was not an English major graduate. 


\section{Doing "Gwu jai syu" (Storybook) in Mr. Chan's class}

Data examples in this section are taken from Mr. Chan's class at the beginning of a reading lesson. The reading passage is a story titled, "Tin Hau, Queen of Heaven", in the storybook "Chinese Myths", which the class uses for English reading. In the immediately preceding period, the students have just finished a dictation exercise. Many students are chatting and laughing with one another in their seats and do not quiet down until turn [459] in the transcript:

\section{Example 1:}

(See appendix for notes on transcription)

(Tape Chan-2.2, Transcriber Counter No.: 457.5)

457.5 T: Alright let's take a break.. then we'll do:: (1.5)

*458.2 Boy: GWU JAI SYU:: <STORYBOOK::>! \{ in Anglicized accent \}

458.5 T: (aah) story//book..

458.7 //Boy: Gwu jai syu <Storybook>! \{ in Anglicized accent $\}$

458.9 Boy: Gwu-jai-syu <Storybook>.

459 T: read.. storybook. SHH:::! \{Ss now quiet down\} Laah.. mh-hou king-gai aa <Okay.. don't chat>! SHH::! King-gai yiu faht-chaau gaa haa- faht-keih $<$ Chatting will be punished by copying- standing $>$. (2) Yau-sik mh fan-jung laa $<$ Let's take a rest of five minutes>. Break.

461 Aa Sir aah ( ? ? ) <Sir, ( ? ?) >

462 SHH!! (6) Ngoh aai neih jihng aa! <I ask you to be quiet!>

\section{(i) A preliminary description:}

The teacher first announces that they will take a break (turn [457.5]) and then something interesting happens: he continues to say, "then we'll do::" which is followed by a 1.5 second pause (turn [457.5]); this is structurally ambiguous: it can be at that moment hearable as a lapse of memory or as an invitation for response from the students, i.e., leaving a blank for the students to fill in what they are going to do. A boy grabs the chance to complete the teacher's sentence (which has been afforded by the fill-in-theblank-type pause) and what he shouts out in a funny English tone from his seat (without raising his hand to self-nominate first, and without standing up while he shouts out his contribution) is even more interesting: "GWU JAI SYU!" (meaning "storybook") (turn [458.2]). "Storybook" is an English word that this boy may very well know as this is not 
the first time they have had "storybook" lessons. One can believe that it is well within his English vocabulary ability to have said "storybook" instead of "gwu jai syu". However, the boy's rendering of "gwu jai syu" seems to be a mocking way of speaking; it mocks the laughable stereotypical way in which an English-speaking person, or "Gwai-Lou" (a Cantonese slang word for foreigners) speaks Cantonese. This way of joking about GwaiLou's typical way of speaking Cantonese has been common in popular Cantonese movies and television dramas.

However, nobody is heard to laugh after that remark by the boy; the videotape shows that most other students have all the time been chatting with their neighbours and few seem to have paid any attention to the teacher or the boy. It is the teacher who seems to be responding to this by an acknowledgement particle "aah" and a reformulation of the boy's contribution into normal English: "storybook" (turn [458.5]).

The video microphone at a back corner of the classroom has picked up the voices of two boys following suit after the first boy's "GWU JAI SYU" remark and the teacher's reformulation. One boy uses the same Anglicized accent (turn [458.7]); the other uses the normal Cantonese tone.

These voices probably are not available to the teacher as the recorder carried by the teacher has not picked up any of these two echoing remarks of the two boys. The teacher goes on to ask the students to be quiet, and they do quiet down for a short time.

\section{(ii) Points of interest:}

First of all, the teacher explicitly announces that they are going to "do storybook" or "read storybook" (turns [457.5]-[459]). He orients his students towards a clear recognition of what they are going to do: "doing, reading storybook" right from the beginning of the lesson. The next thing he does after announcing this lesson agenda is to write out ten reading comprehension questions on the blackboard. Then he asks the students to open the book and to turn to the right unit, and announces the title of the text. The reading task is made very conspicuous right at the beginning of the reading lesson. The students therefore should be oriented towards "doing and reading storybook".

However, the data seem to speak to the contrary. While the above discussion has shown that both the teacher and students in Mr. Chan's class explicitly recognize their lesson activity as "doing and reading storybook", most of the students are actually oriented 
towards talking about things of their own! Both the video- and audio-tapes show that the majority of students in Mr. Chan's class are not attentive to the teacher or what the teacher is doing and saying. Most of the time, most students (e.g., those sitting in middle to back rows) are chatting with neighbours, producing a low white noise that is broken only for very short periods of time, e.g., after the teacher has asked them to be quiet or to stop talking (e.g., turn [459]). There is no unified participation framework in the classroom. Instead, the students are split into numerous more or less separate, simultaneous, small informal conversation groups, with the teacher and a small number of students near the teacher interacting on the front, public stage.

While secondary school students are officially supposed to speak in English in English language lessons in Hong Kong, the students in Mr. Chan's class always speak in Cantonese, whether privately or publicly, except when reading out from the textbook, and when they read, they read haltingly, showing great difficulties in pronouncing many English words in their text. It seems that many students in Mr. Chan's class are neither willing to nor linguistically able to engage in a public, English dialogue with the teacher. While some students are willing to participate in a public dialogue with the teacher, they do so in very unique ways.

For instance, the boy who shouts out "GWU JAI SYU" (turn [458.2]) provides us with evidence that at least some students are willing to take the initiative to participate in a dialogue with the teacher publicly. It has been discussed above that we have reason to believe the boy has the ability to say the English word "storybook", which is officially normal and appropriate in this situation, but he chooses instead to formulate his public contribution in an off-beat way. He has self-selected and grabbed the public discourse slot (afforded by the teacher's 1.5 second pause, see turn [458.2]) as an opportunity to slip in the turn-construction material of his own choice, which does not entirely conform to the teacher's expectations. Although the teacher acknowledges it, he immediately reformulates it into the normal English word (turn [458.5]).

There are at least three different options from which the boy could have chosen: gwu-jaisyu, storybook, and "gwu jai syu". The first is the Cantonese word for "storybook" spoken in normal Cantonese accent. This is an officially unacceptable and inappropriate choice (because this is an English lesson): using it publicly would render him hearable as being blatantly uncooperative with the teacher and unwilling to speak English. However, this may render him hearable to other like-minded students as being "one of us". This 
may be seen as indicative of a Cantonese Culture Island that is opposed to the bilingual middle-class 'Mainland'. On the other hand, a Cantonese word does not seem to be the most suitable material to complete an English utterance.

The second option, "storybook", is officially the most acceptable one. Besides, it seems to be the most suitable material to complete an English utterance. However, using it would render the boy hearable to other students as too cooperative with the teacher and the official lesson agenda ${ }^{3}$.

The third option (actually, this is the option created by the boy himself), "gwu jai syu", a Cantonese word spoken in a stereotypical "Gwai-Lou-speaking-Cantonese" accent, seems to have the merits of both of the above options but not their shortcomings. Using it renders the boy hearable to the teacher not as blatantly uncooperative as the first option; after all, "Tin Hau" (an Anglicized name of the Chinese Heaven-Queen, a word that both their teacher and English storybook use) is an entirely acceptable "English" word. The Anglicized intonation used by the boy when he speaks "gwu jai syu" also fits with the English intonation of the teacher's utterance and so can serve as an admissible candidate to seamlessly complete the English utterance.

On the other hand, he would not be hearable by other students as brown-nosing the teacher or being too cooperative with the English-learning agenda because after all, it is a Cantonese word: it seems that he is not really speaking Gwai-Lou's English; rather, he's mocking Gwai-Lou's Cantonese! This has the additional double effect of being funny and "turning the tables", that is, re-asserting the centrality of Cantonese in relation to English. (Lombardi [1996] has observed a similar phenomenon in Brazil: Portuguese-speaking Brazilians, who are not comfortable with the socioeconomic need to learn English, mock the poor Portuguese of English-speaking North Americans by playing on Brazilian pronunciations of English words).

The reading text itself seems to have provided the boy with the source of creative discourse resources: the reading text is about a Chinese legend with Chinese characters. Normally these students talk about Chinese things in Cantonese, but this strange occasion has required them to talk about Chinese things in English, like a Gwai-Lou talking about Chinese things in their Anglicized Cantonese, e.g., using the Anglicized name, "Tin Hau", 
for the Chinese Heaven-Queen. This seems to be a good context to do a playful mocking of Gwai-Lou's poor Cantonese.

The absurdity of this situation is also something that may prompt a mocking. These students' English is limited and there is evidence that they do not know many of the words in the text. And yet, the content of the story is so boringly familiar that they feel that they do not really need to read the story to know what the story is about (there is some evidence of this in the later phases of the lesson). Some natural questions that they may ask in such a situation seem to be: Why on earth do I need to go through all this pain to read a story that I already know?! What is the point of reading a Chinese story in English? It may make some sense only if I were a Gwai-Lou learning about Chinese things, and Gee, I might just as well get some fun out of this boring and difficult situation by mocking the Gwai-Lou's way of speaking Cantonese!

Another instance of this is seen in turn [458.7]: a boy seemingly following the example of the first boy (turn [458.2]) by echoing it shortly after him. There are two other similar instances in the lesson.

It appears that many other students are engaged in a different kind of playful mocking. Before we can discuss some examples of this, we need to examine the kind of InitiationResponse-Feedback (IRF) discourse format (Sinclair and Coulthard, 1975; Heap, 1988) in Mr. Chan's class that has allowed students to do this different kind of verbal play (cf. Grahame \& Jardine, 1990). Based on analysis of the larger data corpus from Mr. Chan's class (see Lin, 1996b), we can characterize the typical IRF format used in Mr. Chan's class as having the expanded structural sequence shown in Figure 1. 


\section{INSERT FIGURE 1 HERE}

The teacher's reformulation of his L2 initiation in L1 provides a legitimate opportunity for students to contribute their L1 responses, which are, however, ultimately reformulated into English by the teacher in the Feedback slot. This seems to imply that only the English-reformulated responses can count as part of the legitimate corpus (Heap, 1985) of classroom knowledge co-produced by teacher and students through the "I [L2 - L1] -- R [L1] -- F ["aah"/L1 - L2]" discourse format. It is the English-reformulated response that the students will be held accountable for having learnt, and the teacher's "alright?" or "okay?" (i.e., accountability announcements, see Lin, 1996b) comes only after the Englishreformulated response.

Now, what is interesting is how some students make use of this expanded and modified IRF format to slip in their Cantonese verbal play (c.f. Grahame \& Jardine, 1990). Let us look at the following example taken later on from the same lesson:

\section{Example 2:}

$523.8=$ T: What else? (2) Juhng yauh di mat-yeh waan aa <Got anything else to play $>$.. heuidei $<$ they $>$ ?

524.5 =Chan: e::h ... yauh di me- me- gohdi giu-jouh:: (3) there's some- some- something called..

$525 \mathrm{~S}:(? \quad ? \mathrm{aa} !)$

525.5 T: SHH:! Tin-Hauh-Daan yauh di mat-yeh waan aa <During the Heaven-Queen Festival, what's there to play $>$ ? (2) Haa $<$ Yes $>$ ?

526 Chan: Yauh yeh sik <There are things to eat $>$ !=

526.3 =Boy: Yauh yeh waan <There are things to play>=

$526.5=\mathrm{T}$ : Yauh yeh sik aah, juhng yauh ne $<$ There are things to eat, anything else $>$ ?=

526.8 =Girl: Haih yahn dou jidou yauh yeh sik laa! Sai neih ap me <Everybody knows there're things to eat! Who needs you to tell $>$ !

527.2 Some students laugh and a boy is heard to say: (Ye::h! ? ? ji-douh yauh yeh sik gaa laa $<$ know there're things to eat already! $>$ ? )+ = 
The context of this lesson segment would help us appreciate how some students grab the discourse slots afforded by the IRF format to slip in their illegitimate Cantonese verbal play, which is offered either publicly to the teacher and other students, or less publicly, i.e., mainly to themselves (probably for their own amusement).

The teacher has been eliciting responses from students to his question about what people do for fun during the Heaven-Queen Festival. He has reformulated his original L2 initiation in L1, and in a more complete sentence (turns [523.8], [525.5]). A girl (Chan) offers an L1 response (turn [526]): "Yauh yeh sik!" (meaning: There are things to eat!). A boy immediately latches his own contribution, interestingly in the same linguistic pattern as the girl's contribution: "Yauh yeh waan!" (meaning: There are things to play!) (turn [526.3]). Neither the girl's nor the boy's answer seems a satisfactory answer to the teacher's question, for the teacher is asking what there is to play. Still, the girl's answer seems less inappropriate than the boy's, and is hearable as at least a sincere and earnest attempt to offer an answer to the teacher. In fact this question of the teacher's is difficult for the students to answer because the Heaven-Queen Festival is not something these children and their parents really celebrate. It is more important among fishermen, and none of these students have come from a fisherman family background. It is in fact quite remote from their lifeworld experiences. To answer the teacher's question they really have to stretch their imagination a bit (we shall see some evidence of this later on). The teacher recognizes the girl's attempt, too, by reiterating it and thereby acknowledging it, though without clearly affirming it: the particle "aah" (turn [526.5]) attached to the reiteration of the girl's answer indicates his doubts about it (though not very strong ones; this Cantonese particle is usually used to indicate some slight doubts and reservations). He goes on to indicate that there is something else he wants (turn [526.5]).

On the other hand, it is interesting to note that the boy's answer is not acknowledged at all. In fact, it is not hearable as an answer at all (though structurally it looks like an answer and is offered at the appropriate discourse slot); it is hearable more as a parody of the girl's answer, and its parallel structure to the girl's answer makes it a creative extension of the girl's contribution. The boy's latching of his creative linguistic counterpart to the girl's (recognizable "answer to the teacher") has the effect of turning both the girl's and his contributions into neatly parallel structures that nicely make up a verbal rhyme or song. And he publicly offers this verbal play to others. But of course, the teacher does not acknowledge this verbal "contribution" of his. Other students are perhaps too involved in their own "neighbour talk" (i.e., talking to their neighbours) to have paid attention, 
either (so, no laughter from them). Yet, the whole contribution of the boy is hearable more as verbal play than as a real answer to the teacher's question. His way of capitalizing on a legitimate answer (the girl's) to form part of his verbal play and to offer his playful contribution in a sham response linguistic structure offered at the right sequential position of the dialogue is indeed artful and creative. He has also shown himself to be paying close attention to the ongoing official activity, and actively participating publicly (but not in a legitimate way that can be acknowledged by the teacher). In other words, his verbal play is not separate from, but highly intertwined with, the official IRF lesson dialogue: at least, he is offering a sham "response" which structurally fits the slot of the discourse format, though in terms of content, it is in fact what it is: verbal play (i.e., it is verbal play that has the structural appearance of an acceptable response).

The boy's verbal play also seems to have the effect of mocking the girl's hearably eager but obviously unsatisfactory attempt to furnish an appropriate answer to the teacher's question (For obviously the statement "there are things to eat" is not an appropriate answer to the question of "what's there to play?"). Some other students self-select to offer more explicit critical comments (turns [526.8]-[527.2]) on the girl's answer, immediately (and even) after the teacher has tolerantly reiterated and thereby acknowledged it (i.e., without pointing out its awkwardness as an answer to the question). These critical comments seem to have the effect of immediately taking away the credit that the teacher has just (rather unreasonably and tolerantly in the eyes of her consociates) granted to the girl, who seems to be negatively looked upon by her fellow-students as overly eager to answer the teacher's question even when she does not really have an answer.

If we think the boy discussed above is ingenious in his artful ways of intertwining verbal play with the public lesson discourse, there are more surprises in store for us (for more examples, see Lin, 1996b). It is as if there are two activities intertwined: one is the official English reading lesson, directed and staged mainly by the teacher with the help of some willing and some unwilling actors (the students); the other is the impromptu creative verbal play of those unwilling actors, and it takes place in any niche that they can find within the legitimate discourse structure of the official activity. In other words, there seems to be a doubleness to these students' "being" in the classroom: they are both:

(a) limited-English-proficiency students "doing storybook" (officially in English, but in reality with the teacher always providing Cantonese annotations of English 
materials, and the students themselves always providing Cantonese answers [to teacher and textbook questions] which are ultimately reformulated into English by the teacher), and

(b) Cantonese children "doing creative verbal play" (in Cantonese, or in stereotypical "Gwai-Lou's Cantonese").

The two activities are intimately intertwined in the classroom life that they co-construct with the teacher through the creative use of discourse formats in the classroom (cf. Grahame \& Jardine, 1990).

It is obvious that a few of the students do pay attention to the teacher and the ongoing public, official activity, and are very forthcoming, but always in Cantonese and in their own chosen ways (which, however, show great sensitivity to the opportunities and constraints afforded by the Initiation-Response pair or the ordinary Question-Answer adjacency pair), and not in English, nor in ways entirely legitimate or acceptable to the teacher.

Cantonese verbal play seems to be central for a number of students, even as they participate willingly or unwillingly in the public official lesson discourse. This doubleness of their classroom life is constructed through their artful exploitation of the existing public discourse resources for their own playful purposes, which are illegitimate in the English lesson context. One cannot help being struck by the sharp contrast between their highly creative Cantonese linguistic constructions and their highly handicapped English performance (e.g., many of them cannot read out any single complete sentence from the English storybook without difficulty). We seem to see here lively children trapped in an English lesson cage; the constraints notwithstanding, now and then we see their native language creativity bursting out whenever the public discourse format allows a niche for them to put to use their creative indigenous linguistic abilities.

\section{Lively Children Trapped in an Insulated, Socioeconomically Disadvantaged, Cantonese-Dominant World}

The above analysis of the mocking verbal play practices of some working class schoolboys in an English reading lesson shows their ingenious native linguistic and discourse resources. However, one cannot simply romanticize or merely celebrate their native 
language competence without also pointing out the cycle of disadvantage that these Cantonese adolescents seem to be locked in. In the first place, they are situated in Cantonese schoolworlds and communities that are both physically and socially insulated from any native English or English-conversant speech communities. It seems that what are readily available to them as possible identity-making resources come largely from a Cantonese-based popular media culture (comics, TV, pop songs, Cantonese style magazines; more discussion of this in the next section). The English curricular resources (e.g., the teacher's professional expertise, the appropriateness of the lesson materials, the organization of the lesson tasks and activities) also prove to be inadequate to arouse their interest in or to enable them to participate in any English communicative, literacy, or sociocultural activities. On the contrary, doing English lessons in such a manner and context as illustrated by the lesson excerpts above seems to have the effect of alienating these Cantonese-dominant students, pushing them further away from any possibility of developing an interest in English as a language and culture that they can appropriate for their own communicative and sociocultural purposes (unlike their middle-class bilingual counterparts in Hong Kong; see Lin, 1996b).

Their creative self-asserting verbal play seems to reflect their effort in trying to make such an alienating lesson situation more bearable: to create fun for themselves by drawing on their indigenous linguistic and discourse resources. However, their Cantonese world remains insulated and they remain outside of the English sociocultural world, of which they can hardly become a participating member (Lave \& Wenger, 1991). The English lessons seem to have the effect of pushing them to further insulate themselves in their Cantonese-based sociocultural world and of denying them any possibility of developing a Cantonese-English bilingual identity and competence, which characterize the socioeconomically successful bilingual middle-class in Hong Kong. In the next section, I shall discuss why access to a bi/trilingual identity is going to be difficult for these Cantonese-dominant working class children and why post-1997 Hong Kong does not seem to hold much promise of improving their lot unless important changes take place in the social selection mechanism (Bourdieu \& Passeron, 1977) as well as in their schools and communities.

\section{Language, Identity, and Social Class in Hong Kong: Before and after July 1st, 1997}


Current academic discussions of the identity/ties of Hong Kong people in pre- and post1997 Hong Kong often leave out the dimension of social class. However, as Chun in a recent article comparing the discourses of identity in Taiwan, Hong Kong, and Singapore puts it:

Hong Kongers really had no identity as a people in the sense of being bound by shared assumptions and values. The free market institutions which gave rise to illusions of an autonomous culture industry also gave rise to mentalities and lifestyles that were effectively divided on the basis of class and education. (Chun, 1996, p. 59; italics in original)

Hong Kongers seem to live in an island not only geographically but also culturally and politically. Under British colonial rule, youth in Hong Kong have been brought up in an apolitical culture and Hong Kongers in the 1980s and 90s seem to find it difficult to identify themselves with any political mainstream: Britain, the People's Republic of China, or Taiwan (Chun, 1996). The long-term political and sociocultural separation from Mainland China has also set Hong Kong people and their Mainland counterparts onto very different sociocultural paths with different identities. The British Hong Kong government's encouragement of an apolitical and a highly capitalistic and commercial culture in Hong Kong has contributed to the channelling of Hong Kong people's attention and energies to the pursuit of lifestyles that can be characterized chiefly by the dual activities of competitive money-making and popular entertainment-seeking. In a sense, Hong Kong people have demonstrated a peculiar kind of island identity that is best defined not by any political allegiance but by a sense of local Cantonese-based Chinese cultural identity, which is not deliberately imposed or encouraged by any governmental force, but has been chiefly fueled by the free market institutions (e.g., the media and entertainment industries) which have given rise to a widely shared, Cantonese-based, popular culture since the 1970s.

With this sociocultural and economic backdrop in mind, it is not surprising to find Hong Kong youth who cannot answer questions about what they do during the Tin Hau (Heavenly Queen) Festival (see lesson excerpts above). Those parts of the Chinese traditions and customs which belonged to a bygone agrarian Chinese culture have been replaced by the newly emerging local (Hong Kong) capitalist, Cantonese-based, entertainment culture which interestingly is also a hybrid of East and West, of English, Japanese, and Cantonese pop cultures (e.g., the hybrid linguistic genres and frequent code- 
mixing practices found in popular comics, magazines, movies, TV, radio, songs). In this sense, the emerging Hong Kong cultural identity that we witness in the 80s and 90s is a hybrid pop-culture-based identity, which is also very much local Cantonese-based, despite the pervasive mixing of English words and indigenized Japanese words in the Cantonese language used by Hong Kong people: it is very much tied to the modern capitalistic, commercial lifestyles and economic and entertainment activities of people in Hong Kong, void of any larger political allegiance or nationalist overtones.

While this local Cantonese-based, apolitical, cultural identity is more or less available to most Hong Kong people including the largely Cantonese-monolingual working classes, the multiple identities that Hong Kongers are alleged to be able to shift among in different situations to their own advantage (see John Joseph, this volume) are, however, not accessible to all social classes. It seems that only the upper and middle class Hong Kongers, who are to a greater extent bi/trilingual (i.e., apart from being fluent in Cantonese, also with a higher degree of fluency in English, and recently also in Putonghua, the Standard spoken language of China), can have access to those socioeconomically important identities such as an international/cosmopolitan identity, a professional/business executive identity, or a linguistic and cultural broker identity in the booming China trade activities, for instance. Indeed, the issue is not what identity Hong Kongers have, but what identiTIES that different social groups in Hong Kong (do not) have access to and are (not) able to take on in different activities with different interactants, with different consequences including important socioeconomic and material ones (e.g., access to or denial of higher education and high-income job opportunities). In this paper, I have tried to illustrate how the combined workings of the socioeconomic domination of English, an alienating English curriculum, and the resistance of working class children contribute to these children's encapsulation in a largely Cantonese sociocultural world. While the encapsulation and insularity can offer a source of group identity and pride, it does not enable these children to have access to other socioeconomically valued identities. In a real sense, they are trapped in an island of disadvantage.

Will post-1997 Hong Kong witness a better lot for these children? Will these marginalized youth embrace the new Chinese nationalist and cultural identity, which is to be encouraged/imposed (depending on one's perspective) via the new curriculums that are likely to be introduced in post-1997 (e.g., new civic education and Putonghua curriculums)? Will that new identity enable them to have more socioeconomic mobility and social prestige? Will it offer them pride and security as well as better life chances? 
It seems that only time can give full answers to these questions, though some "informed guesses" can be made here. To make any predictions regarding these issues, it seems that one has to consider at least the following two questions: (1) Have there been any significant changes in the social selection mechanism in Hong Kong after it changed from a British colony to a Special Administrative Region (SAR) of China? (2) Have there been any significant changes in the linguistic and demographic make-up of Hong Kong's population with increasing immigration from Mainland China after July 1st, 1997 ?

Regarding the first question, all current evidence seems to point to a post-1997 scenario in which English will still be the chief gate-keeping language for major institutions of socioeconomic mobility. For instance, most higher education institutes maintain that they will keep English as the chief medium of instruction after 1997, with the prestigious University of Hong Kong and the Hong Kong University of Science and Technology being the most outspoken about the importance of upholding the English medium policy and the international status of their institutes. Other higher institutes such as the City University of Hong Kong have also reiterated such a policy. The SAR government is staffed by more or less the same English-educated personnel, headed by Mrs. Anson Chan, who is graduate of English from the University of Hong Kong, and has been serving the Hong Kong colonial government before the 1997 transition. The only difference, it seems, after July 1st, 1997, is that in addition to (not in the place of) English, Putonghua will be a gate-keeping language for entrance to the civil service. It thus only adds to the barriers for working-class Cantonese-dominant graduates to enter the civil service: now they have to be trilingual instead of bilingual to be considered for these well-paying and high-status jobs.

The dominance of English in the global economy (Pennycook, 1994; Martin-Jones \& Heller, 1996) also makes it unlikely for Putonghua to replace English in the Hong Kong job market. However, it is very likely for Putonghua to be an additional required language, as China trade continues to boom and Hong Kong continues to serve as a linguistic and business broker between Mainland China and other countries. Without English, as many have argued, Hong Kong will lose its importance to China as its window on the world. Hong Kong's usefulness to China and the rest of the world, it seems, depends on its service as a linguistic, cultural, and business broker. To play that role, it needs a workforce that is conversant in both English and Chinese (i.e., Standard written Chinese and Putonghua). The socioeconomically mobile and successful in the post-1997 
SAR will be those who master "yih-mahn saam-yyuh", as the recent trendy Hong Kong saying goes: meaning those who are "biliterate (in English and Standard written Chinese) and trilingual (in English, Putonghua, and Cantonese)". These will be people who can have access to multiple identities (e.g., Chinese, Southern Chinese, Hong Kong, Westernized, modernized, cosmopolitan, international, professional) with biliterate and trilingual resources. The life chances of the encapsulated Cantonese working-class children do not look to be improving in post-1997 Hong Kong. In fact, it seems that it will be even more difficult for them to achieve socioeconomic mobility: they will have to master two additional languages that do not have any real communicative role in their lifeworld. However, whether Putonghua will permeate their lifeworld in post-1997 Hong Kong depends on the answer to the second question: will there be any significant changes in the linguistic and demographic make-up of Hong Kong's population with increasing immigration from Mainland China?

The answer to the second question is even harder to construe. While China's leaders have promised to strictly control immigration from China to Hong Kong, there are estimated to be hundreds of thousands of Southern Mainland Chinese children born of Hong Kong fathers or mothers waiting to cross the Mainland-Hong Kong border to be reunited with their parents. Currently no statistics are available to inform us of their language use patterns. Informal contacts with schools which have taken in immigrant children give the author the impression that these children come from diverse linguistic backgrounds: some speak a home language which is neither Cantonese nor Putonghua (e.g., Chiuchowese), some also speak a little Putonghua but no Cantonese, but most of them have zero acquaintance with English.

With the introduction of Putonghua as a compulsory subject starting from primary school, and the influx of South Mainland Chinese children into the school system, it is hard to predict what will become the language of the school playground. While Mainland Chinese immigrant children are likely to suffer social ostracization from local Cantonese children because many of them do not speak Cantonese (or speak it with an accent), their Putonghua resource (for those who have this) might elevate their status among local Cantonese children when Putonghua is a compulsory and valued subject in the school system. It is, however, difficult to give a precise projection at this stage about what would happen to the sociocultural and linguistic matrix of the school playground and of the local Cantonese communities. It seems that there can be a number of possible scenarios. The worst possible scenario will be one of a social division between the local 
working class Cantonese children and the Mainland Chinese immigrants, though both groups suffer low social mobility because of their lack of English resources. A more positive possible scenario is the hybridization of the local Cantonese communities so that there will be a greater acceptance of multilingualism and the use of Putonghua as a lingua franca between Mainland Chinese immigrants and the local Cantonese. Another likely scenario is the assimilation of the Mainland immigrants into the Cantonese communities with Cantonese remaining the everyday lingua franca and the local communities remaining largely Cantonese-dominant and monolingual (e.g., the new immigrant children gradually losing their home dialects and being assimilated into the Cantonese communities).

\section{Conclusion}

Which of the scenarios outlined above will be witnessed by post-1997 Hong Kong should not, however, be left entirely to chance or fate. Educationists, the school system, parents, and the post-1997 Hong Kong government need to take a proactive role and be seen to pursue policies and practices that encourage multilingualism among school children as well as in society so that the diverse linguistic resources (and with them diverse identities) of the new Mainland Chinese immigrants will not be lost in the local Cantonesedominant communities. The post-1997 Hong Kong government must work towards preventing the possible social divide between Mainland Chinese immigrants and local Cantonese and the possible resistance to Putonghua among the latter. This, however, cannot be done by legislation alone (e.g., laws to ensure the right to speak and maintain one's home dialect). A variety of culturally compatible bridging programmes (Lin, 1996c) must be developed to bridge the many linguistic gaps that exist between the home world and the school world of these disadvantaged children (including both new immigrants and local working class Cantonese children): e.g., the gaps between Cantonese and Standard written Chinese/Putonghua, between Cantonese and English, between different home dialects and Standard Chinese, and between different home dialects and English. Whether these children can embrace the new Chinese nationalist identity as one of their multiple identities and not merely as an imposed identity, and whether post-1997 Hong Kong will witness a society that both values, and provides children with access to, multilingual resources or a society deeply/bitterly divided on the basis of social class, education, and ethnic origins (e.g., Mainland immigrant vs. local Cantonese) will depend on what school principals, teachers, parents, educationists, community leaders, and the government are willing to do beyond July 1st, 1997 to help disadvantaged, non-

English/Putonghua-speaking children to expand their sociocultural and linguistic world to 
access a world of multilingual and multicultural resources. It is only with these resources can the next Hong Kong generation go beyond their island identity and access multiple identities that are needed for both socioeconomic success and cultural vitality in an increasingly diversified and pluralistic world in the coming century.

\section{Acknowledgements:}

I am indebted to the editor for his many helpful comments and suggestions. Special thanks go to Suzanne Wong Scollon, Ron Scollon, John Flowerdew, and David Li for sharing with me their views on some of the issues raised in this paper. The limitations of the paper are, however, my own. 


\section{Notes}

1. All personal names are pseudonyms.

2. Secondary schools in Hong Kong are roughly classified into five bands, according to the primary-school-leaving-examination results of their students. Band 1 students are the highest scoring students while Band 5 students are the lowest scoring students in the examination.

3. This interpretation is based on my understanding of the students' culture through my informal contact and chatting with the students. A common phrase they use to describe a fellow student suspected of doing brown-nosing is, "bok mat aa!?", meaning "to gain what!?". The phrase is usually spoken disapprovingly to describe a fellow student who takes the initiative to speak English in class. 


\section{References}

Bourdieu, P. (1982/1991). Language and symbolic power (G. Raymond \& M. Adamson, Trans.). Cambridge, Mass.: Cambridge University Press. (Original work published 1982)

Bourdieu, P., \& Passeron, J.-C. (1977). Reproduction in education, society and culture (R. Nice, Trans.). London: Sage.

Chun, A. (1996). Discourses of identity in the changing spaces of public culture in Taiwan, Hong Kong and Singapore. Theory, Culture and Society, 13(1), 51-75.

Grahame, P. R. \& Jardine, D. W. (1990). Deviance, resistance, and play: A study in the communicative organization of trouble in class. Curriculum Inquiry, 20(3), 283304.

Heap, J. L. (1985). Discourse in the production of classroom knowledge: Reading lessons. Curriculum Inquiry, 15(3), 245-279.

Heap, J. L. (1988). On task in classroom discourse. Linguistics and Education, 1 , 177198.

Ho, H.C.Y. (1994). The state of the economy. In P.K. Choi \& L.S. Ho (Eds.) The other Hong Kong report: 1993, pp. 75-94. Hong Kong: The Chinese University Press.

Lave, J., \& Wenger, E. (1991). Situated learning: Legitimate peripheral participation. Cambridge: Cambridge University Press.

Lin, A. M. Y. (1996a). Bilingualism or linguistic segregation? Symbolic domination, resistance, and code-switching in Hong Kong schools. Linguistics and Education, $\underline{8}(1), 49-84$.

Lin, A. M. Y. (1996b). Doing-English-lessons in secondary schools in Hong Kong: A sociocultural and discourse analytic study. Unpublished doctoral dissertation, University of Toronto, Canada.

Lin, A. M. Y. (1996c). A culturally compatible English curriculum for Cantonese children in Hong Kong: An alternative to dominant TEFL methodologies. Paper presented at the International Conference on Language Rights, June 23-25, 1996, Polytechnic University, Hong Kong.

Lombardi, J. (1996, January 5). Mocking English and Spanish in Brazil. E-mail message sent to the Language-Culture Electronic Discussion Network, University of Chicago. 
Martin-Jones, M., \& Heller, M. (1996). Introduction to the special issue on eduation in multilingual settings: Discourse, identities and power. Linguistics and Education, 8(1), 3-16.

Pennycook, A. (1994). The cultural politics of English as an international language. London: Longman.

Sinclair, J., \& Coulthard, M. (1975). Towards an analysis of discourse. London: Oxford University Press. 


\section{APPENDIX: NOTES ON TRANSCRIPTION}

(1) English is transcribed orthographically and Cantonese is transcribed in the Yale system. English translations of Cantonese utterances are placed in pointed brackets $<>$ following the Cantonese utterances. The English utterances, Cantonese utterances, and the English translations are each written in a different font type.

(2) The numerals preceding each turn is the transcribing machine counter no.; a speaking turn is referred to as: turn [counter no.]

(3) "T" represents "Teacher"; "S": Student; "Ss": Students; "Boy" or "Girl" stands for any male or female student voice picked up by the tape and whose identity not available. Words like "Girl 1", "Girl 2", "Boy 1", "Boy 2", "S1", "S2", etc. are used to differentiate between two different boys/girls/students speaking one after the other. The same words may be used at other points in the transcript to differentiate between another two students speaking, but that does not indicate that they are the same two students who have spoken earlier.

(4) Pauses and gaps: A short pause is indicated by ".." and a longer one by "...".

Pauses longer than 0.5 second are indicated by the number of seconds in brackets, e.g., (2) indicates a pause of 2 seconds. Gaps between speaking turns are indicated by: ((no. of seconds)), e.g., ((5)) indicates a gap of 5 seconds.

(5) Simultaneous utterances: The point at which another utterance joins an ongoing one is indicated by the insertion of two slashes in the ongoing turn. The second speaker and her/his utterance(s) are placed below the ongoing turn and are preceded by two slashes, e.g.:

017.8 T: //Sheung-hok-kei <Last term> \{spoken in an Anglicized tone $\}$ no, haha! $\{\mathrm{T}$ sounds amused

017.8 //Boy 3: Mat-yeh giu jouh sports day aa $<$ What is a sports day $>$ ?

If the first ongoing turn is very long, the second utterance is placed under the line of the ongoing turn where the point of intersection appears, e.g.:

508.5 T: Mh-hm mh-hm \{clearing his throat $\}$ (3) mh-hm alright \{all students are quiet now $\}$ (2) today we'll talk about unit 3, (2) open your book (2) story//book (1.5) who don't have the storybook, == 510.5 //Boy: storybook

$511==\mathrm{T}$ : raise up your hand (4.5), I want to make sure everybody can read the story, right you two share- share the book. (2.5) How about you? (3) Take 
out the book. ( $3 \mathrm{sec}$ ) Right you two share the book (3.5) Jeung-YiuhJung.. yeh aah. (5) Right unit three, Tin Hau, Queen of Heaven.=

(6) Contiguous utterances: Two equal signs $==$ are used to connect different parts of a speaker's utterance when those parts constitute a continuous flow of speech that has been carried over to another line, by transcript design, to accommodate an intervening interruption; see example under (5) above.

The latching of a second speaking turn to a preceding one is indicated by a single equal sign, "=", e.g.:

517 Boy: (Bin yau ying-man ge?) $<$ (How come there's English?) $>=$ 517.3 =T: Shh: do you know .. Tin Hau?

(7) Contextual information: Significant contextual information is given in curly brackets: e.g., $\{$ Ss laugh $\}$

(8) Accentuation: Accentuated syllables are marked by capitalization. Lengthening of sounds is marked by colons: e.g. SHOU::LD

(9) Transcriptionist doubt: Unintelligible items or items in doubt are indicated by question marks in parentheses or the words in doubt in parentheses, e.g.:

517 Boy: (Bin yau ying-man ge?) < (How come there's English?) $>$ 524 Girl 1: Ngoh faan ( ? ? ) < I returned ( ? ? )>

(10) Underlined words in the utterances are words read out from a text.

(11) All personal names are pseudonyms. Names spoken in Cantonese are substituted by a Cantonese pseudo-name, e.g., Chahn-Ji-Mahn; names spoken in English are substituted by an English pseudo-name, e.g., Robert. Original names of places close to the schools are substituted by other place names.

(12) Asterisks (*) are used to indicate turns of particular analytical interest. 
Figure 1: A structural characterization of a routine dialogue in Mr. Chan's reading lesson

(1) Teacher-Initiation [L2 - (gap) - L1]=

(2) =Student-Response [L1]

(3) Teacher-Feedback ["aah"/L1 - L2]

Note: The square brackets [ ] enclose the turn-construction materials in each slot. There is often a gap (in terms of seconds) before the L1 reformulation of the L2 initiation. The "=" sign represents the latching of student responses to the teacher's L1-reformulated initiation. The "aah" is a conversation particle acknowledging and affirming students' responses; it is the usual particle used for this function. However, sometimes, the teacher reiterates the student response in L1, and the acknowledgment particle is not used; the reiteration is itself hearable as an acknowledgment. 